\title{
РАЗРАБОТКА ПРОГРАММНО-АППАРАТНОГО КОМПЛЕКСА МОНИТОРИНГА ПАРАМЕТРОВ ГИДРАВЛИЧЕСКОГО РАЗРЫВА ПЛАСТА ПРИ ЭКСПЛУАТАЦИИ МЕСТОРОЖДЕНИЙ НЕФТИ И ГАЗА МИКРОСЕЙСМИЧЕСКИМИ МЕТОДАМИ.
}

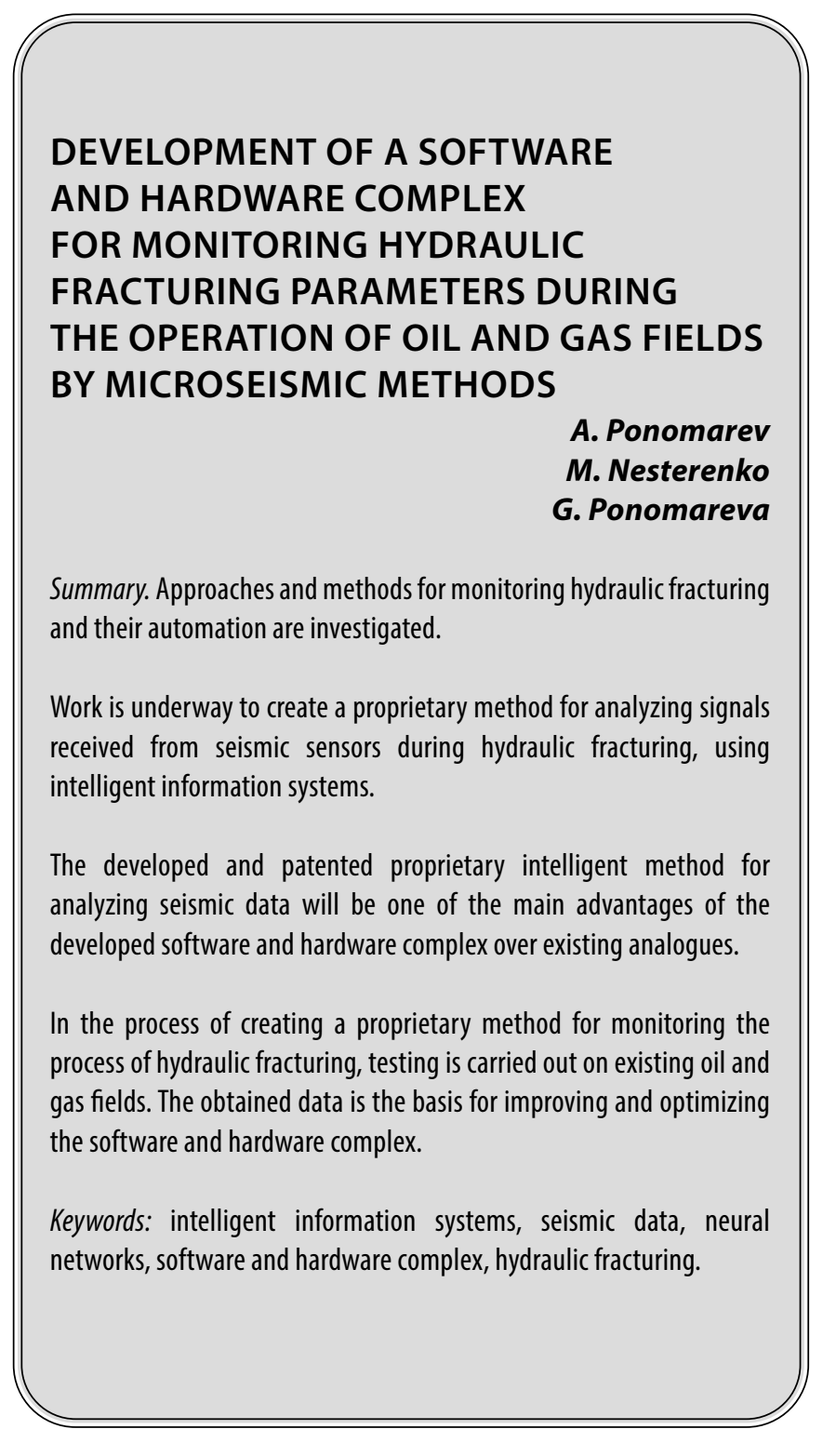

\section{Введение}

4 еловечество нуждается в энергетических ресурсах. И с каждым годом потребность становится выше, т.к. популяция на планете увеличивается в геометрической прогрессии. Основной источник энергии - различные фракции нефти. Потому вопросы
Пономарев Алексей Андреевич Аспирант, ФГБУН «Оренбургский Федеральный исследовательский чентр УрО РАН», Оренбург alexceuponomarev@mail.ru

Нестеренко Максим Юрьевич

Д.г.- м.н., ФГБУН «Оренбургский Федеральный исследовательский чентр УрО РАН», Оренбург

n_mu@mail.ru

Пономарева Галина Алексеевна К.г-м.н., дочент, ФГБОУ ВО «Оренбургский государственный университет», Оренбург galy.ponomareva@mail.ru

Аннотация. Исследованы подходы и методы мониторинга гидравлического разрыва пласта и их автоматизации.

Ведутся работы по созданию собственного метода для анализа сигналов, полученных с сейсмических датчиков во время гидравлического разрыва пласта, с использованием интеллектуальных информационных систем.

Разработанный и запатентованный собственный интеллектуальный метод анализа сейсмических данных будет являться одним из основных преимуществ разработанного программно-аппаратного комплекса перед существующими аналогами.

В процессе создания собственного метода наблюдения за процессом гидроразрыва пласта проводится апробация на существующих месторождениях нефти и газа. Полученные данные - основа для улучшения и оптимизации программно-аппаратного комплекса.

Ключевые слова: интеллектуальные информационные системы, сейсмические данные, нейронные сети, программно-аппаратный комплекс, гидроразрыв пласта. 
лежи, обладающие низкой проницаемостью пластов. При этом нефть, извлечённая из таких залежей, по своим характеристикам вполне сопоставима с нефтью традиционных месторождений. К другой группе относятся месторождения тяжёлой и высоковязкой нефти [1, 2, 3]. Одни из основных способов добычи для таких месторождений это гидравлический разрыв пласта (ГРП), многозабойные скважины и их комбинации. При оценке результатов ГРП используются сейсмические данные, записанные в ходе данного процесса. Однако из-за низкого соотношения сигнал/шум результат оценки может быть ошибочным. В связи с развитием технологий и интеллектуальных систем возможно их применение в данной области $[4,5,6,7]$. Они помогут в улучшении получаемых результатов даже с использование классических методов расчетов данных [8].

\section{Сушествуюшие метолы фильтрашии} сейсмического сигнала

Исследованы подходы и методы мониторинга гРП и их автоматизации [9, 10, 11, 12]. При регистрации сейсмических событий датчиками возникают помехи - шум, который присутствует в полученном от датчиков сигнале. Дальнейшее использование сигнала с подобными помехами приводит к некорректным и/или неточным результатам оценки результата ГРП, потому возникает потребность в обработке и улучшении соотношения сигнал/шум. Это можно сделать с использованием известных методов фильтрации. Фильтрация является важной составляющей любого этапа обработки сейсмических сигналов, и ее как таковую иногда бывает трудно вычленить в отдельный блок. Фильтрация нужна, если есть основания полагать, что полезные сигналы имеют четкие критерии, по которым их можно отличить от помех. Очень часто используется частотная фильтрация, если полезные сигналы имеют отличия в спектральном составе. В частности, режекторная фильтрация весьма эффективна для удаления промышленных узких гармонических помех (25, 50, 100 Гц и др.). При регистрации широкополосными каналами наиболее востребована полосовая фильтрация, снижающая уровень любых сигналов за пределами полезной полосы частот. При наблюдениях ГРП использовалась полосовая фильтрация в различных диапазонах. Какой именно диапазон фильтровать, зависит от индивидуальной картины волнового поля на каждой отдельной станции. Для шумовых условий наиболее информативным является диапазон 15-40 Гц. Фильтрация, выполняемая на полученных данных, помимо частотной и скоростной избирательности учитывала также неидентичность сейсмических каналов. Данный вид фильтрации приводит полевые записи на всем полезном частотном диапазоне к виду, который бы соответствовал записям, полученным абсолютно идентичными приборами. Такая коррекция возможна благодаря специально организованным подготовительным работам. В условиях наблюдений поверхностными станциями актуальна скоростная фильтрация сигналов, позволяющая различить импульсы от подземных и поверхностных источников. Скоростной фильтр позволяет уверенно различать сигналы от источников на поверхности, многие из которых распространяются со скоростью звука ( 330 м/с), что в несколько раз ниже скорости сейсмических волн, приходящих из нижнего полупространства. На этапе расстановки сейсмических фаз и последующей локации очагов немаловажное значение приобретает поляризационная фильтрация, возможность которой обеспечивается наличием трехкомпонентных записей. Однако определить, какой метод фильтрации необходим для каждого индивидуального месторождения, затруднительно, а в совокупности с большим объемом обрабатываемой информации (большое количество поступающих данных с датчиков каждую секунду в течении нескольких часов) может быть действительно трудоемким процессом для специалиста. В результате чего было принято решение использовать интеллектуальные информационные системы (ИИС), а точнее нейронные сети, которые позволяют обрабатывать большое количество информации за малый промежуток времени, могут подстраиваться под определенные задачи, присутствует возможность их обучения на существующих примерах, дальнейшее использование полученных результатов для их оценки, повторного обучения и корректировки алгоритма, подбор оптимального метода фильтрации под конкретные параметры каждого месторождения и т.п. Предложена методология и методы исследования, основанные на интеллектуальных информационных системах, в частности, нейронных сетях, в комбинации с известными методами фильтрации, используемые, для улучшения соотношения сигнал/шум и снижения паразитных помех, полученных с сейсмических датчиков с места проведения ГРП. Длительный и сложный процесс определения параметров трещины ГРП, низкая скорость анализа полученных сейсмических данных, низкое соотношение сигнала/ шум, ошибки в оценке результатов и эффективности ГРП - основные вопросы, с которыми сталкиваются при проведении ГРП. В связи с большим объемом обрабатываемой информации необходимо использование интеллектуальных информационных систем. Их преимущество в скорости и точности обработки большого объема информации, возможности корректировать получаемый результат и повторно его использовать.

\section{Риски ошибок}

Развиваются системы визуализации многомерных массивов информации, доступные как в виде коммерческого ПО, так и в виде свободно распространяемых 
инструментов с функционалом, который постоянно пополняется продвинутыми пользователями. Сектор разведки и добычи нефтегазовой отрасли является одним из наиболее рискованных с точки зрения принятия капиталоёмких решений по проведению разведочных работ и выбору системы разработки того или иного месторождения. Это связано с высоким уровнем неопределённости геологической информации, что, в свою очередь, обусловлено физическими ограничениями технологий сейсморазведки. Проще говоря, если в прискважинной зоне информация о структуре и особенностях углеводородных пластов достаточно полна, то при проведении процесса ГРП из-за индивидуальных параметров месторождения, объема закачки расклинивающего агента и прочих работ реальный результат проведения гидроразрыва пласта, направление, величина и другие характеристики трещины достоверно не известны. При этом, по объёму геолого-технологических, логистических, финансовых и других данных, интерпретация разноформатных и разномасштабных данных вышла на новый уровень. Петрофизики и геологи научились строить двумерные и трёхмерные геологические модели залежи, на основе которых строятся гидродинамические модели. Последние используются для моделирования течений в пластах и расчёта прогнозной добычи при разных сценариях разработки. Такой подход добавляет компонент прогнозного моделирования, основанного на уравнениях математической физики, в систему принятия решений по разработке. За время жизни месторождения генерируется большое количество различных данных. Сейсмические данные представляют собой временные ряды и трёхмерные изображения; данные внутрискважинных измерений (каротажа) - набор векторов; данные гидродинамических испытаний скважин - временные ряды; данные исследования керна - таблицы, двумерные и трёхмерные изображения; данные исследования пластовых флюидов - таблицы; данные каротажа при бурении - временные ряды, векторы; данные поверхностной телеметрии при бурении (поверхностный каротаж) временные ряды; данные по геологотехническим мероприятиям на скважинах - текст, временные ряды и таблицы; профили добычи и данные телеметрии насосов - временные ряды различного разрешения. Данные различны по формату, весьма объёмны (сейсмические исследования генерируют до нескольких десятков терабайт) и поступают постоянно. Если в окрестности скважины мы можем сказать, что знаем о геологических особенностях достаточно много, то, на расстоянии 10-100 м от скважины наши познания о фильтрационно-ёмкостных свойствах пласта представляют собой, скорее, оценки. Большое количество данных, получаемых при разведке и бурении, используется для построения моделей пласта с целью оптимизации схемы разработки месторождения, являющейся, наряду с раз- витием инфраструктуры, основной статьёй капитальных затрат нефтегазовых компаний. Неопределённости в данных обусловливают неопределённости в результатах гидродинамического моделирования, на основе которых принимаются капиталоёмкие решения по разработке. Руководители, принимающие стратегические решения с временным горизонтом влияния на добычу, достигающим десятков лет, должны учитывать риски, связанные с этими неопределённостями. Разработка и внедрение прогнозных систем на основе анализа данных [13] всех упомянутых типов позволит эффективно снижать неопределённости и соответствующие финансовые риски. Данные по добыче [14], гТМ, телеметрия насосов, телеметрия и каротаж при бурении используются для оперативного управления добычей и разработкой. Решения, принимаемые на основе этих данных, непосредственно влияют на объёмы операционных затрат [15]. Рекомендательные системы, построенные на основе детерминистических и data-driven моделей процессов добычи и бурения, позволят существенно оптимизировать эту статью затрат. В качестве очевидных приложений методов машинного обучения в совокупности с математической оптимизаций можно выделить следующие:

- методы предсказания нестандартных режимов работы оборудования (anomaly detection) для оптимизации работы буровых установок, насосов, энергетических установок;

- методы распознавания образов (глубокие свёрточные нейронные сети) для автоматизации процессов построения геологических моделей с использованием данных со всех масштабов измерения (сейсмика, каротаж, керн) и минимизации неопределённостей геологических моделей $[16,17]$;

- методы извлечения информации из документов для создания вопросно-ответных систем (электронных советников) операторам-добытчикам, буровикам, геологам- разработчикам;

- методы уменьшения размерности задач мат. физики для создания быстрых систем скрининга вариантов разработки месторождений. Алгоритмы, использующие методы машинного обучения и анализа данных не являются абсолютно новыми для нефтедобывающей отрасли. Так, например, 8 октября 2018 года вышла статья «Возможности электромагнитного мониторинга ГРП для оценки стимулированного объема пород», авторы Г.С. Григорьев, М.В.Салищев, НаучноТехнический Центр «Газпром нефти» (ООО «Газпромнефть НТЦ»), П.Ю. Пушкарев, МГУ имени М.В. Ломоносова [18]. В 2017 году в «РН-УфаНИПИнефть» создан первый в Евразии промышленный симулятор гидравлического разрыва пласта (ГРП) - программный комплекс 
«РН-ГРИД», который позволяет точно описывать сложную геометрию трещины, возникающей в породе при проведении ГРП. В 2018 году дочернее сервисное предприятие «Роснефти» «РН-ГРП» полностью перешло на «РН-ГРИД» при проведении операций ГРП, став, таким образом, первым российским сервисным предприятиям, осуществившим импортозамещение программного обеспечения для моделирования ГРП [19].

\section{Научная новизна}

Изучается возможность создания собственного интеллектуального метода для анализа сигналов, полученных с сейсмических датчиков во время гидравлического разрыва пласта. Будут использованы интеллектуальные информационные системы, в комбинации с классическими методами фильтрации сейсмических сигналов. Традиционно для контроля результатов операции ГРП используется подход, основанный на применении оборудования и программного обеспечения для ЗД - сейсморазведки. Данный метод выполняется после проведения ГРП в отсутствии шума от работы насосов ГРП, и позволяет с определенным разрешением наблюдать результат ГРП - трещины в породах пласта, как видимые участки разуплотнения в породах. Данный подход имеет ряд недостатков - недостаточное разрешение метода, возможность контроля только по окончании операции ГРП и высокая стоимость (необходимо вибровоздействие и регистрация с помощью сотен акселерометров). Предлагаемый программно-аппаратный комплекс основан на использовании 10-20 велосиметров, установленных в радиусе 500-2500 метров от скважины. Программно-аппаратный комплекс снимает показания скоростей смещения грунта в процессе ГРП, для калибровки используются записи операции перфорации прострелочно-взрывным методом. Большое количество записей позволяет получить избыточную информацию и с использованием интеллектуальных методов выделить полезный сигнал из шума, вызываемого работой насосов ГРП. Таким образом, предлагаемый подход позволяет регистрировать параметры сейсмических событий, вызываемых трещинообразованием при гидравлическом разрыве пласта. Предлагаемый метод позволяет выявить направление трещинообразования и их длину.

\section{Конструктивные требования}

Создание автоматизированной системы мониторинга предполагает создание программно-аппаратного комплекса с использованием языка программирования, среды разработки и сейсмологического оборудования. Автоматизация в данном случае подразумевает некоторое участие разработчика в процессе настройки и корректировки деятельности нейросети, которая заберет на себя работу, связанную с анализом и фильтрацией сейсмического сигнала. Основными этапами создания автоматизированной системы мониторинга параметров гидравлического разрыва пласта при эксплуатации месторождений нефти и газа микросейсмическими методами будут являться:

1. Проектирование автоматизированной системы мониторинга.

2. Разработка автоматизированной системы мониторинга.

3. Лицензирование автоматизированной системы мониторинга.

4. Тестирование автоматизированной системы мониторинга.

5. Внедрение в организациях-заказчиках.

6. Сопровождение, развитие и корректировка автоматизированной системы мониторинга.

7. Основными этапами работы автоматизированной системы мониторинга будут являться:

8. Расстановка, настройка и калибровка сейсмических датчиков [20].

9. Загрузка данных по месторождению. Загрузка микросейсмических данных [21]. Загрузка скорректированных данных.

10. Анализ нейронной сетью источников шума, подбор оптимального алгоритма фильтрации.

11. Анализ микросейсмических данных нейронной сетью.

12. Обработка и фильтрация сигнала нейронной сетью.

13. Анализ специалистом полученных результатов обработки сигнала нейронной сетью.

14. Передача результатов обработки (улучшенный сигнал) для дальнейшего использования или корректировка алгоритма нейронной сети и возврат ко второму пункту на повторный анализ.

\section{Зак^ючение}

Исследованы подходы и методы мониторинга гидравлического разрыва пласта и их автоматизации. В процессе создания собственного метода наблюдения за процессом гидроразрыва пласта проводится апробация на существующих месторождениях нефти и газа. Полученные данные являются основой для улучшения и оптимизации программно-аппаратного комплекса.

Разработанный и запатентованный собственный интеллектуальный метод анализа сейсмических данных будет являться одним из основных преимуществ автоматизированной системы перед существующими аналогами. 


\section{ЛИТЕРАТУРА}

1. Виноградова Т.Е. Особенности микрокомпонентного состава сверхвязкой нефти / Т.Е. Виноградова, Г.А. Пономарева // Региональные проблемы геологии, географии, техносферной и экологической безопасности (Оренбург, 18-20 ноября 2019): сб. статей всероссийской научно-практической конференции. - Оренбург: 000 «норма», 2019.-С. 6-9.

2. Пономарева Г.А. Геохимические особенности распределения платиноидов в нефтегазовых месторождениях Оренбургской области / Г.А. Пономарева // Новые направления работ на нефть и газ, инновационные технологии разработки их месторождений, перспективы добычи нетрадиционного углеводородного сырья; сб. статей всероссийской научно-практической конференции. — Оренбург: 000 «ТИПОГРАФИЯ «АГЕНТСТВ0 ПРЕССА», 2019.— C. $98-102$.

3. Пономарева Г.А. Форма нахождения ванадия в нефти Тананыкского месторождения Оренбургской области / Г.А. Пономарева // Новые направления работ на нефть и газ, инновационные технологии разработки их месторождений, перспективы добычи нетрадиционного углеводородного сырья; сб. статей всероссийской научно-практической конференции. — Оренбург: 000 «ТИПОГРАФИЯ «АГЕНТСТВО ПРЕССА», 2019.—C. 95-98.

4. Grechka V., Werner M.H., Microseismic Monitoring, Tulsa: Society of Exploration Geophysicists, 2017. 471 c.

5. Бондарёв В.И., Крылатков С.М. Основы обработки и интерпретации данных сейсморазведки: учебник для вузов. Часть ІІІ. Екатеринбург: Изд-во УГГГА, 2001. - $198 \mathrm{c}$

6. Seismic monitoring in mines. Ed. by A.J. Mendecki. London: Chapman\&Hall, 1997. 262 p.

7. Круг П.Г. Нейронные сети и нейрокомпьютеры: Учебное пособие по курсу «Микропроцессоры».— М.: Издательство МЭИ, 2002.— 176 с.

8. Tchebotareva I.I., Nikolaev A.V., Sato H. Seismic emission activity of Earth's crust in Northern Kanto, Japan. Physics of the Earth and planetary interiors. № 120.- 2000. Р. $167-182$.

9. Пономарев А.А. Проектирование системы мониторинга параметров гидравлического разрыва пласта при эксплуатации месторождений нефти и газа микросейсмическими методами / А.А. Пономарев. // ІХ Всероссийская конференция с международным участием. 2019. С. 483.

10. Пономарев А.А. Применение математических методов при решении геоэкологических проблем месторождений углеводородного сырья/А.А. Пономарев, М.Ю. Нестеренко // Уральская минералогическая школа. 2016. Т. 80. С. 73.

11. Ponomarev A.A. Modeling and prediction of hydrodynamic processes on the oil and gas fields / A.A. Ponomarev // Modern Science. 2017. № 2. C. $15-17$.

12. Кислов К.В., Гравиров В.В. Использование искусственных нейронных сетей в классификации зашумленных сейсмических сигналов // Сейсмические приборы. 2016. Т. 52, № 2. С. 46-64.

13. К.В. Кислов, В.В. Гравиров // Глубокие искусственные нейронные сети как инструмент анализа сейсмическихданных // 2017 г. К.В. Кислов, В.В. Гравиров

14. Пономарев А.А. Микросейсмический мониторинг и процесс гидро-разрыва пласта при эксплуатации месторождений углевородородов / А.А. Пономарев, М.Ю. Нестеренко // Вестник современных исследований.—- 0мск, 2018. - С. 650-651. ISSN2541-8300

15. Александров В.М. Применение метода микросейсмомониторинга в задачах нефтепромысловой геологии [Текст]: монография / В.М. Александров. Тюмень: ТИУ, 2016. - 93 c.

16. M. Nesterenko, A. Tsviak, 0. Kapustina, A. Nesterenko, S. Nikiforov Dangerous geodynamic processes of the Eastern Orenburg. E3S Web Conf. Volume 169, 2020. Actual Problems of Ecology and Environmental Management: Cooperation for Sustainable Development and Environmental Safety

17. Maksim Nesterenko, Aleksey Tsviak, and Vladimir Belov. Natural and technogenic geodynamic processes in the south Ural. E3S Web of Conferences Volume 208 (2020) First Conference on Sustainable Development: Industrial Future of Territories (IFT 2020) Yekaterinburg, Russia, September 28-29, 2020.

18. Григорьев Г.С., Салищев М.В., Пушкарев П.Ю. Возможности электромагнитного мониторинга ГРП для оценки стимулированного объема пород // Геофизика. 2018. № 4. С. 90-93.

19. Rosneft. [Электронный ресурс] — Режим доступа: https://www.rosneft.ru/press/news

20. Seis-Monitor Seismology Geophone. [Электронный ресурс] — Режим доступа: http://www.geospace.com/seis-monitor-seismology-geophone.

21. Guralp systems Instruments. [Электронный ресурс] — Режим доступа: http://www.guralp.com/products/instruments

( П Пономарев Алексей Андреевич ( alexceuponomarev@mail.ru ), Нестеренко Максим Юрьевич ( n_mu@mail.ru ),

Пономарева Галина Алексеевна ( galy.ponomareva@mail.ru ).

Журнал «Современная наука: актуальные проблемы теории и практики» 